\title{
Adaptation to Leftward Shifting Prisms Alters Motor Interhemispheric Inhibition
}

\author{
Elisa Martín-Arévalo ${ }^{1,2}$, Selene Schintu'1,2,3, Alessandro Farnè ${ }^{1,2,4}$, \\ Laure Pisella ${ }^{1,2, \dagger}$ and Karen T. Reilly ${ }^{1,2, \dagger}$
}

${ }^{1}$ ImpAct team, Lyon Neuroscience Research Center, INSERM U1028, CRNS-UMR5292, 16 Ave. Doyen Lépine, 69676 Bron Cedex, France, ${ }^{2}$ Lyon 1 University, F-69373 Lyon, France, ${ }^{3}$ Behavioral Neurology Unit, National Institute of Neurological Disorders and Stroke, National Institutes of Health, 10 Center Bethesda, MD, USA and ${ }^{4}$ Hospices Civils de Lyon, Neuro-immersion \& Mouvement et Handicap, F-69676 Lyon, France

Address correspondence to Karen T. Reilly and Elisa Martín-Arévalo, Integrative, Multisensory, Perception, Action and Cognition team (ImpAct team), Lyon Neuroscience Research Center, INSERM U1028, CRNS-UMR5292, 16, Ave. Doyen Lépine, 69676 Bron Cedex, France. Email: karen.reilly@inserm.fr (K.T.R.) and emartina@ugr.es (E.M.-A.)

${ }^{\dagger}$ Authors contributed equally to this work.

\begin{abstract}
Adaptation to rightward shifting prisms (rightward prism adaptation, RPA) ameliorates neglect symptoms in patients while adaptation to leftward shifting prisms (leftward prism adaptation, LPA) induces neglect-like behaviors in healthy subjects. It has been hypothesized that prism adaptation (PA) modulates interhemispheric balance between the parietal cortices by inhibiting the posterior parietal cortex (PPC) contralateral to the prismatic deviation, but PA's effects on interhemispheric inhibition (IHI) have not been directly investigated. Since there are hyper-excitable connections between the PPC and primary motor cortex (M1) in the left hemisphere of neglect patients, we reasoned that LPA might mimic right hemisphere lesions by reducing parietal IHI, hyper-exciting the left PPC and PPC-M1 connections, and in turn altering IHI at the motor level. Namely, we hypothesized that LPA would increase IHI from the left to the right M1. We examined changes in left-toright and right-to-left IHI between the 2 M1s using the ipsilateral silent period (iSP) (Meyer et al. 1995) before and after either LPA or RPA. The iSP was significantly longer after LPA but only from left-to-right and it did not change at all after RPA. This is the first physiological demonstration that LPA alters IHI in the healthy brain.
\end{abstract}

Key words: ipsilateral silent period, prism adaptation, TMS, visuospatial neglect

\section{Introduction}

Visuospatial neglect manifests as a failure to attend, respond, or orient to stimuli in the contralesional hemispace and is most common after right hemisphere (RH) lesions (Vallar 1993). Prism adaptation (PA) is both a promising rehabilitation technique for this complex, multicomponent syndrome, and a research tool for investigating the mechanisms underlying neglect (Luauté et al. 2006; Redding and Wallace 2006; for reviews). Indeed, PA can ameliorate neglect symptoms when vision is shifted rightward (rightward prism adaptation, RPA) (Rossetti et al. 1998;
Farnè et al. 2002; Frassinetti et al. 2002; Pisella et al. 2002; Serino et al. 2006) and induce neglect-like behavior in healthy subjects when vision is shifted leftward (leftward prism adaptation, LPA) (Michel et al. 2003; Schintu et al. 2014).

Pisella et al. (2006; see also Striemer and Danckert 2010) have proposed that PA relies on the integrity of the cerebellum (Weiner et al. 1983; Pisella et al. 2005) and affects cognition by first inhibiting the posterior parietal cortex (PPC) contralateral to the prismatic deviation and, in turn, modulating interhemispheric balance. Converging support for this claim, albeit 
indirect, comes from functional neuroimaging and electroencephalography studies showing bilateral changes in PPC functional activity after PA (Saj et al. 2013; Crottaz-Herbette et al. 2014; Martín-Arévalo et al. 2016).

Interhemispheric balance, or rather imbalance, has also been implicated in neglect following RH damage. Kinsbourne's theory of Hemispheric Rivalry (1977) postulates that each hemisphere contains a spatial attention processor for the opposite half of space but that there is "an imbalance in lateral orienting tendencies" (1977, p. 46) making these processors asymmetric such that the left hemisphere (LH) exerts a stronger rightward orienting tendency $(1973,1987)$. The theory posits that "opposing directional turning tendencies are in mutually inhibitory competition" (1977, p. 71) or "reciprocal inhibition" (1987, p. 76). As such, unilateral stroke in either hemisphere will weaken orienting to contralesional space and release the other hemisphere from interhemispheric inhibition (IHI). The consequences of $\mathrm{RH}$ stroke will be more severe because the initially weaker orienting to leftward space will not only be further weakened, but also because orienting to rightward space will be strengthened due to the release of the LH from inhibition (Kinsbourne 1970, 1977, 1987).

The Hemispheric Rivalry theory is one of the main theories in the neglect literature, and it is supported by data showing that recovery of neglect correlates with restoration of interhemispheric balance between the 2 PPCs (Corbetta et al. 2005; He et al. 2007), and more specifically with inhibition of the intact LH (Oliveri et al. 2001; Brighina et al. 2003; Nyffeler et al. 2009; Cazzoli et al. 2012; Salatino et al. 2014). Further support comes from the observation that neglect patients have hyper-excitable connections between the left PPC and left primary motor cortex (M1) (Koch et al. 2008) and that improvements observed after RPA are even greater when RPA is combined with excitation of the right (damaged) PPC by anodal transcranial direct current stimulation (tDCS) (Làdavas et al. 2015).

The Hemispheric Rivalry theory can be summarized by 2 main ideas: 1) hemispheric asymmetry for attention and 2) reciprocal inhibition between hemispheres. One implicit assumption of this theory (e.g., see Szczepanski and Kastner 2013) is that this reciprocal inhibition is of equal strength. Recent evidence suggests, however, that IHI between the parietal cortices is asymmetric. Using a triple pulse transcranial magnetic stimulation (TMS) paradigm, Koch et al. (2011) found that a single TMS pulse on the right PPC inhibited parietal-to-motor connections in the $\mathrm{LH}$, but not the reverse. In light of this result we suggest that some phenomena explained by Hemispheric Rivalry in terms of asymmetries in attentional orienting e.g., alterations in visuospatial biases in healthy subjects by LPA but not RPA (Colent et al. 2000; Michel et al. 2003; Schintu et al. 2014), or by inhibition of the right (Fierro et al. 2000; Bjoertomt et al. 2002; Nyffeler et al. 2008; Giglia et al. 2011) but not the left PPC (Fierro et al. 2000; but see Szczepanski and Kastner 2013), or even the predominance of neglect after RH lesion (Jacobs et al. 2012; for a review), might also be partially explained by asymmetric IHI between the parietal cortices.

Here, we investigated whether PA affects IHI by examining changes in left-to-right and right-to-left IHI at the motor level using the ipsilateral silent period (iSP; Meyer et al. 1995, see Materials and Methods for more details). Studies in patients with abnormalities of the corpus callosum (Meyer et al. 1995, 1998; Schmierer et al. 2000; Wolters et al. 2004; Wittstock et al. 2007) suggest that the iSP results from activation of interhemispheric transcallosal inhibitory connections between the motor cortices (Meyer et al. 1998; Chen et al. 2003; Daskalakis et al. 2003; Giovannelli et al. 2009). We predicted that LPA-which induces neglect-like behaviors in the healthy brain-would mimic the effect of RH lesions by inhibiting the right PPC. Then, via the reduction of right-to-left parietal IHI it would increase left PPC excitability. This, in turn, would increase the excitability of left PPC-M1 connections (Karabanov et al. 2012; Chao et al. 2013)-similar to what has been observed in neglect patients (Koch et al. 2008)—and it would consequently increase IHI from left-to-right M1 (see Fig. 1). In contrast, given that RPA would inhibit the left PPC, which according to Koch et al. (2011) does not inhibit its homolog, we predicted no subsequent increase of right PPC-M1 connectivity and thus no change in IHI between the 2 M1s after RPA. To test our predictions, we adapted healthy subjects to either LPA or RPA and recorded the left-to-right and right-to-left iSP before and after PA.

\section{Materials and Methods}

The iSP (Meyer et al. 1995, 1998) is the brief interruption of tonic voluntary muscle activity following stimulation of the M1 ipsilateral to the contracting muscle. It is assumed to reflect the function of transcallosal fibers that mediate an inhibitory effect from the stimulated M1 to the nonstimulated, voluntarily active, M1 in the opposite hemisphere (Chen et al. 2003; Daskalakis et al. 2003; Giovannelli et al. 2009). This assumption is based upon studies in patients with callosal lesions (Meyer et al. 1995, 1998) and neurological disorders such as multiple sclerosis, amyotrophic lateral sclerosis, corticobasal degeneration or progressive supranuclear palsy (Schmierer et al. 2000; Wolters et al. 2004; Wittstock et al. 2007) all of which show a delayed or absent iSP, indicating that the iSP reflects interhemispheric cortico-cortical inhibitory mechanisms mediated by transcallosal fibers.
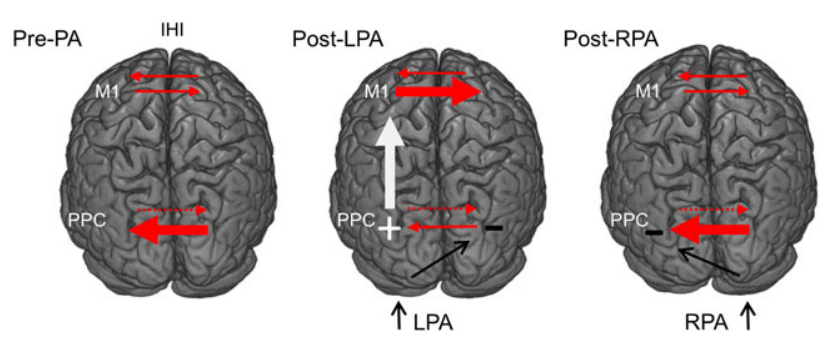

Figure 1. Figure displays hypothesized pathways of action of PA. "Red arrows" represent interhemispheric inhibitory connections both at baseline (left panel) and after PA (middle and right panels). "Black arrows" represent the action of PA as proposed by Pisella et al. (2006): PA (both LPA and RPA) critically depends on the cerebellum and exerts its subsequent after-effects by initially inhibiting the PPC contralateral to the prism deviation. The mechanism of action of LPA (middle panel) would be as follows: LPA would mimic the effect of RH lesions by reducing right-to-left parietal IHI (Koch et al. 2011) and increasing left PPC excitability (Kinsbourne 1977). Given the functional connections between PPCM1 (Karabanov et al. 2012; Chao et al. 2013), their hyperexcitability in the LH of neglect patients (Koch et al. 2008), and the critical fact that anodal tDCS over PPC modifies intrahemispheric circuits within M1 (Rivera-Urbina et al. 2015), LPA would increase excitatory intrahemispheric connections in the LH ("white arrow") and subsequently increase IHI from left-to-right at the motor level (M1). We predict no change from right-to-left M1 because changes in IHI in one direction can occur without modifying the reverse (Murase et al. 2004; Stinear et al. 2015). In contrast, because RPA (right panel) inhibits the left PPC (black arrow), based on the recent finding by Koch et al. (2011) that left PPC does not seem to inhibit its homolog, we predicted no subsequent change in right PPC excitability and thus no change of IHI between the 2 M1s after RPA. Note that we did not predict a direct action of PA on the PPC-M1 contralateral to the prism deviation via a reduction of intrahemispheric PPC-M1 connectivity because cathodal tDCS over PPC has been shown not to alter intracortical motor circuits within the same hemisphere as measured by short-interval intracortical inhibition or facilitation (SICI or ICF) (Rivera-Urbina et al. 2015). 


\section{Participants}

A total of 24 healthy volunteers (fourteen females, mean age = 21.0 years, standard deviation $[\mathrm{SD}]=2.1$ ) participated in the study; 12 participants per PA group (LPA -6 females, mean age $=$ 21.0 years, $\mathrm{SD}=2.1 ; \mathrm{RPA}-8$ females, mean age $=21.1$ years, $\mathrm{SD}=2.2$ ). All participants were right-handed as assessed by the Edinburgh Handedness Inventory (Oldfield 1971). They were undergraduate students, naive to the purpose of the experiment, had normal or corrected-to-normal vision, gave written informed consent and were paid for their participation. None of the participants had a history of neurological or psychiatric diseases. The study was approved by the local ethics committee and was conducted in accordance with the ethical standards of the 1964 Declaration of Helsinki (last update: Seoul, 2008).

\section{General Procedure}

The experiment consisted of 2 iSP measurement sessions, one before and one after a PA procedure; and in each session, iSP was measured from left-to-right and right-to-left with the order counterbalanced across participants. Half of the subjects were adapted using LPA and half using RPA. Throughout the experiment, participants were comfortably seated on an armchair and their head was positioned on a neck-rest during the iSP measurements and on a chin-rest during the PA procedure.

\section{Prism Adaptation}

Participants were adapted to prisms that deviated their vision by $15^{\circ}$ (left or right) using a procedure, stimuli, and material that conformed to well-established protocols running in our laboratory (see e.g., Schintu et al. 2014). Participants were seated with their head positioned on a chin-rest at a distance of $57 \mathrm{~cm}$ in front of a white horizontal board on which 3 target dots (subtending $0.5^{\circ}$ of visual angle) were positioned at $0^{\circ}$, $-10^{\circ}$, and $+10^{\circ}$ from their body midline. All participants used their right index finger during the PA procedure.

At the start of the PA procedure, participants placed their right index finger on the starting position-just in front of their chest. Participants could not see their hand when it was in the starting position or during the first third of the pointing movement. First, they made 10 pointing movements to a position straight-ahead of their body's midline with their eyes closed to avoid visual feedback regarding their movements. They were told to look at the central target $\left(0^{\circ}\right)$, close their eyes, point to the target while keeping the eyes closed, and then return their hand to the starting position. The average of these 10 pointing movements gave the open-loop pointing measurement. During adaptation, participants were fitted with prism goggles that deviated their visual field by $15^{\circ}$ either leftward (LPA group) or rightward (RPA group).

While wearing the goggles, participants performed a total of 150 verbally instructed pointing movements toward the right $\left(+10^{\circ}\right)$ and left $\left(-10^{\circ}\right)$ targets in a pseudorandom order. They were instructed to make a ballistic movement and to correct any errors on the subsequent movement. Following the adaptation phase, the goggles were removed and open-loop pointing was tested straight after adaptation (Post 1 ) as well as at the end of the experiment (Post 2; i.e., around $12 \mathrm{~min}$ after the end of adaptation) to assess whether the sensorimotor after-effects were still present. The difference between open-loop pointing measures before and after adaptation was used to determine the size of the after-effect.

\section{Electromyography Recording and TMS Procedure}

Electromyography (EMG) and motor evoked potentials (MEPs) were recorded from the first dorsal interosseous (FDI) of both hands using $\mathrm{Ag}-\mathrm{AgCl}$ surface electrodes (Delsys). EMG signals were collected and digitized at a sampling rate of $1984 \mathrm{kHz}$ using an analog-to-digital converter (Power 1401II, Cambridge Electronics Design). TMS over M1 (LH or RH) was performed with a figure-of-eight coil (outer diameter of each wing: $90 \mathrm{~mm}$ ). The coil was connected to a Magstim $200^{2}$ magnetic monophasic stimulator (The Magstim Company) and was held tangential to the scalp at an angle of approximately $45^{\circ}$ from the midline (Di Lazzaro et al. 1998). Participants were comfortably seated on an armchair and their head was positioned on a neck-rest.

The session began by first determining the hotspots for both FDIs, defined as the optimum site that evoked the largest contralateral MEP in the relaxed muscle. This site was then used to determine resting motor threshold (rMT)-the minimum stimulus intensity to elicit MEPs $>50 \mu \mathrm{V}$ in at least 5 out of 10 consecutive trials (Triggs et al. 1994; Chen et al. 2003; Rossini et al. 2015). Hotspot and rMT measurements were both performed in one hemisphere and then the other, with the order counterbalanced across participants. Thresholds were similar for both the LPA and RPA groups (LPA: $38.2 \%$ of maximum stimulator output (MSO); RPA: $35.1 \%$ MSO).

iSP measurements were taken at the FDI hotspot, which was recorded in a neuronavigation system (Brainsight, Rogue Research) in order to monitor the coil position throughout the experiment and to return to the same coil position after PA.

\section{Maximal Voluntary Contraction and iSP Measurements}

Prior to performing the iSP measurements, participants were instructed to produce their maximal isometric voluntary contraction (MVC) force in FDI by squeezing a small memory-foam object as hard as possible between their thumb and index finger. They performed 6 consecutive 3- to 4-s trials with a break between each trial. Visual feedback of the EMG activity in the FDI was displayed on a monitor and MVC was calculated as the average of the maximum integrated EMG value from each of the 6 trials. This procedure was repeated for both hands, with the order counterbalanced across participants. MVC values were similar for both the LPA and RPA groups (LPA: $0.9 \mathrm{mV}$; RPA: $1.1 \mathrm{mV})$. After the hotspots, thresholds and MVCs were calculated for each hemisphere and each hand, iSP measurements were performed first in one hemisphere then in the other.

Throughout the experiment, participants were required to squeeze the memory-foam object and maintain a tonic FDI contraction of between 30 and 50\% of MVC. Visual feedback was provided by a screen in front of the participants, which displayed the integrated EMG signal as well as horizontal cursors indicating 30 and $50 \%$ of MVC. Once the FDI contraction level was between the 2 horizontal cursors, 20 iSPs were recorded by stimulating at $120 \%$ of rMT (Giovannelli et al. 2009; Fling et al. 2013). The intertrial interval varied randomly between 6 and $10 \mathrm{~s}$ and participants were told that they could relax for a few seconds after each TMS pulse. Trials on which contraction level was too high or too low were discarded off-line (these represented less than $1 \%$ of all trials). EMG activity in the hand 
contralateral to the TMS was monitored to ensure that this hand remained relaxed throughout the experiment.

\section{Data Analysis}

iSP onset latency and duration were calculated using the method described previously by Garvey et al. (2001) implemented in a custom-made MatLab program (MathWorks). A single iSP measurement was made from the 20 TMS trials from each participant by rectifying and averaging EMG activity in the hand ipsilateral to the TMS for $100 \mathrm{~ms}$ before (baseline) and $180 \mathrm{~ms}$ after the TMS pulse. The following equation was used to calculate $99.7 \%$ of possible prestimulus EMG data point values: (average baseline EMG \pm ([maximum value of baseline EMG - minimum value of baseline $E M G] \times 2.66$ ). The onset and offset of the isP were defined as the first of 5 consecutive data points that fell below the lower limit calculated from the equation above (onset) and the first data point that fell above the higher limit calculated by the equation above (offset) if more than $50 \%$ of the data points in the previous $5 \mathrm{~ms}$ were also above the lower limit (Garvey et al. 2001). Duration was then calculated from the onset and offset values. We also measured the depth of the iSP using the 2 different methods described by Jung and Ziemann (2006): 1) the minimum EMG level during the iSP (depth iSP-max) and 2) the average EMG level during the iSP (depth iSP). Both measures were expressed as a percentage of the average baseline EMG level.

All iSP measurements (iSP onset latency, iSP duration, depth iSP-max and depth iSP) were analyzed separately using mixed effects analysis of variance (ANOVA) with Hemisphere (LH vs. $\mathrm{RH}$ ) and Time (pre-PA vs. post-PA) as within-participant factors and PA group (LPA vs. RPA) as a between-participant factor. Significant effects were further analyzed using Bonferroni post hoc tests and the critical $\alpha$ level was set at 0.05 . All data are presented as mean $\pm \mathrm{SD}$.

\section{Results}

\section{Prism Adaptation}

The average landing position during open-loop pointing immediately before PA (baseline), immediately after PA (Post 1) and after all TMS measurements (Post 2) was used to assess whether participants adapted to prisms and whether they remained adapted until the end of the experiment $(\sim 12 \mathrm{~min}$ after PA). To do this, we calculated the difference between Post 1 and baseline and Post 2 and baseline. Since the sign of the shift depends upon the direction of the prisms, we submitted the absolute value of the shift to a mixed ANOVA with Time (Post 1 vs. Post 2) as a within-participant factor and PA group (LPA vs. RPA) as a between-participant factor. This analysis revealed a significant effect of Time $\left(F_{1,22}=95.25, P<0.01, \eta_{p}^{2}=\right.$ 0.81 ) with greater adaptation at Post 1 than Post 2 (7.0 vs. $4.2 \mathrm{~cm}$ from the central target). The main effect of Group was significant $\left(F_{1,22}=7.92, P=0.01, \eta_{p}^{2}=0.26\right)$, with greater adaptation in the RPA than in the LPA group (6.4 vs. $4.7 \mathrm{~cm})$. The interaction between Time and PA group was also significant $\left(F_{1,22}=7.98\right.$, $\left.P<0.01, \eta_{p}^{2}=0.26\right)$. Bonferroni post hoc tests revealed a greater adaptation in the RPA than in the LPA group at Post 1 (8.3 vs. $5.7 \mathrm{~cm}, P<0.01)$ but no difference between the groups at Post 2 ( 4.6 vs. $3.7 \mathrm{~cm}, P=0.70$ ), suggesting that in both groups participants remained significantly and equally adapted until the end of the iSP experimental session.

\section{iSP Measurements}

Table 1 shows the mean and SD for all 4 iSP parameters separated by PA group (LPA, RPA), Hemisphere (LH, RH) and Time (Pre-PA, Post-PA). Separate mixed ANOVAs were conducted on the iSP onset latency, iSP duration, depth iSP-max and depth iSP with the following factors: Hemisphere (LH vs. RH) and Time (Pre-PA vs. Post-PA) as within-participant factors and PA group (LPA vs. RPA) as a between-participant factor. Note that none of the iSP measurements differed between hemispheres or groups before the adaptation procedure (all Ps $>0.14$ ). Contralateral MEP amplitudes were also analyzed. This analysis revealed no significant main effects or interactions (all Ps $>0.074$ ).

"isP duration" was longer in the LPA than in the RPA group $\left(F_{1,22}=6.49, P=0.02, \eta_{p}^{2}=0.22\right)$ and the interaction between Time and PA group $\left(F_{1,22}=9.46, P<0.01, \eta_{p}^{2}=0.30\right)$ was significant, with a longer iSP duration Post-PA in the LPA group and no change in the RPA group, but none of the Bonferroni post hoc tests were significant (all Ps $>0.16$ ). The interaction between Hemisphere and Time $\left(F_{1,22}=4.32, P=0.04, \eta_{p}^{2}=0.16\right)$ was also significant, with a longer iSP duration after PA for the LH and a shorter iSP duration after PA for the RH, but none of the Bonferroni post hoc tests were significant (all Ps > 0.13). Neither the main effects of Hemisphere and Time nor the 2-way interaction between PA group and Hemisphere was significant (all Ps $>0.14$ ) but the 3-way interaction between Hemisphere, Time and PA group $\left(F_{1,22}=4.53, P=0.04, \eta_{p}^{2}=0.17\right)$ was significant. Bonferroni post hoc tests revealed only one significant effect: in the LH of the LPA group iSP duration was longer after PA $(P=0.02$; all other post hoc t-tests, Ps > 0.11).

In a complementary analysis, we separated the data from the LPA and RPA groups and performed separate 2-way repeated measures ANOVAs on the data from each group with the factors Hemisphere and Time. In the LPA group, the interaction between Hemisphere and Time was significant $\left(F_{1,11}=8.17, P<0.01, \eta_{p}^{2}=\right.$ 0.42 ), with a significantly longer iSP duration after PA for the $L H$ $(P=0.02)$ but no difference for the RH $(P=0.16)$. In the RPA group, neither the main effects nor the interaction was significant

Table 1. iSP measurements for each experimental condition

\begin{tabular}{|c|c|c|c|c|c|c|c|c|}
\hline & \multicolumn{4}{|l|}{ LPA } & \multicolumn{4}{|l|}{ RPA } \\
\hline & \multicolumn{2}{|l|}{ LH (left FDI) } & \multicolumn{2}{|c|}{ RH (right FDI) } & \multicolumn{2}{|l|}{ LH (left FDI) } & \multicolumn{2}{|c|}{ RH (right FDI) } \\
\hline & Pre-PA & Post-PA & Pre-PA & Post-PA & Pre-PA & Post-PA & Pre-PA & Post-PA \\
\hline iSP duration (in ms) & $27.91(4.84)$ & $34.16(6.50)$ & $29.83(4.08)$ & $29.16(4.49)$ & $25.66(3.33)$ & $24.33(3.10)$ & $25.33(3.05)$ & $24.08(2.26)$ \\
\hline iSP onset latency (in ms) & $46.41(2.40)$ & $45.41(2.19)$ & $44.33(1.90)$ & $45.41(1.94)$ & $49.83(2.89)$ & $52.33(3.49)$ & $47.41(2.42)$ & $48.01(2.25)$ \\
\hline Depth iSP-max (in \%) & $73.24(5.55)$ & $71.41(5.32)$ & $72.42(3.02)$ & $70.88(5.34)$ & $61.22(5.15)$ & $62.56(4.74)$ & $60.76(6.61)$ & $61.06(3.89)$ \\
\hline Depth iSP (in \%) & $52.39(6.47)$ & $52.92(4.93)$ & $53.81(3.47)$ & $53.56(5.91)$ & $64.10(3.87)$ & $63.30(3.69)$ & $60.17(5.16)$ & $60.31(4.33)$ \\
\hline
\end{tabular}

All data presented are the mean with the SD in parentheses. 
(all Ps $>0.25$ ). The effect observed at the group level in the LPA group in both the 3-way and 2-way ANOVAs was observed in each of the 12 subjects and is illustrated in Figure 2, which shows the averaged, rectified EMG obtained from one representative subject in the LPA group. This figure shows that iSP duration was significantly longer after LPA for the LH (left FDI) whereas in the $\mathrm{RH}$ it did not change.

"iSP onset latency" was significantly later in the RPA than in the LPA group $\left(F_{1,22}=6.64, P=0.01, \eta_{\mathrm{p}}^{2}=0.22\right)$. The main effect of Hemisphere was also significant $\left(F_{1,22}=4.99, P=0.04, \eta_{p}^{2}=0.18\right)$, as the onset latency was later for the LH. None of the other main effects or interactions reached significance (all Ps $>0.07$ ).

For iSP "depth" measurements, the main effect of PA group was significant for both depth iSP-max and depth iSP $\left(F_{1,22}=13.01, P<0.01, \eta_{p}^{2}=0.37\right.$ and $F_{1,22}=7.56, P=0.01, \eta_{p}^{2}=$ 0.25 , respectively), as both the minimum and average EMG levels during the iSP were greater in the LPA group. For depth iSP, the interaction between Hemisphere and PA group was also significant $\left(F_{1,22}=5.17, P=0.03, \eta_{p}^{2}=0.19\right)$, as in the RPA group the depth iSP was greater for the LH than for the RH, whereas in the RPA group there was no difference between hemispheres, but note that none of the Bonferroni post hoc tests were significant (all Ps > 0.19). None of the other main effects or interactions for either depth iSP-max or depth isP reached significance (all Ps $>0.23$ ).
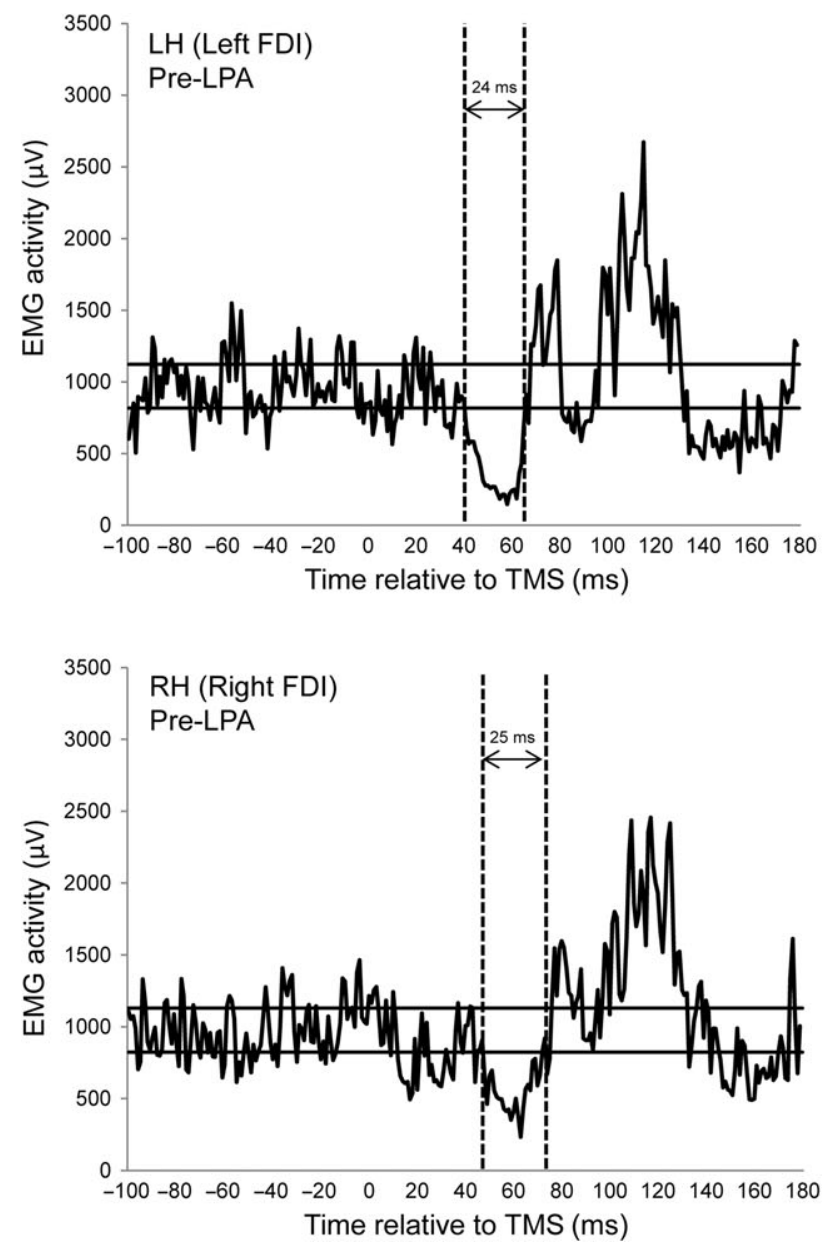

\section{Discussion}

We examined changes in left-to-right and right-to-left IHI at the motor level before and after LPA or RPA in healthy subjects. We found that only LPA modulated IHI between the 2 motor cortices and only from the left to the right motor cortex. This is the first physiological demonstration that PA alters IHI.

\section{Symmetric and Asymmetric After-Effects of PA}

In healthy subjects, PA to a leftward or rightward deviation produces equal but opposite sensorimotor after-effects (Colent et al. 2000; Michel et al. 2003; Schintu et al. 2014). In contrast, only adaptation to a leftward deviation produces visuospatial aftereffects (Colent et al. 2000; Michel et al. 2003; Striemer et al. 2006; Nijboer et al. 2010). The fact that we observed a change in IHI after LPA but not RPA suggests that increased IHI from the leftto-right motor cortex reflects changes in higher level cognitive processes rather than low-level sensory-motor processes. Higher level cognitive after-effects could be linked to direct connections from the cerebellum to the PPC, whereas low-level sensorymotor processes generated by both LPA and RPA could be linked to direct connections between the cerebellum and M1. This is supported by evidence from patients showing that bilateral lesions to PPC disrupt visuospatial after-effects (Striemer et al.
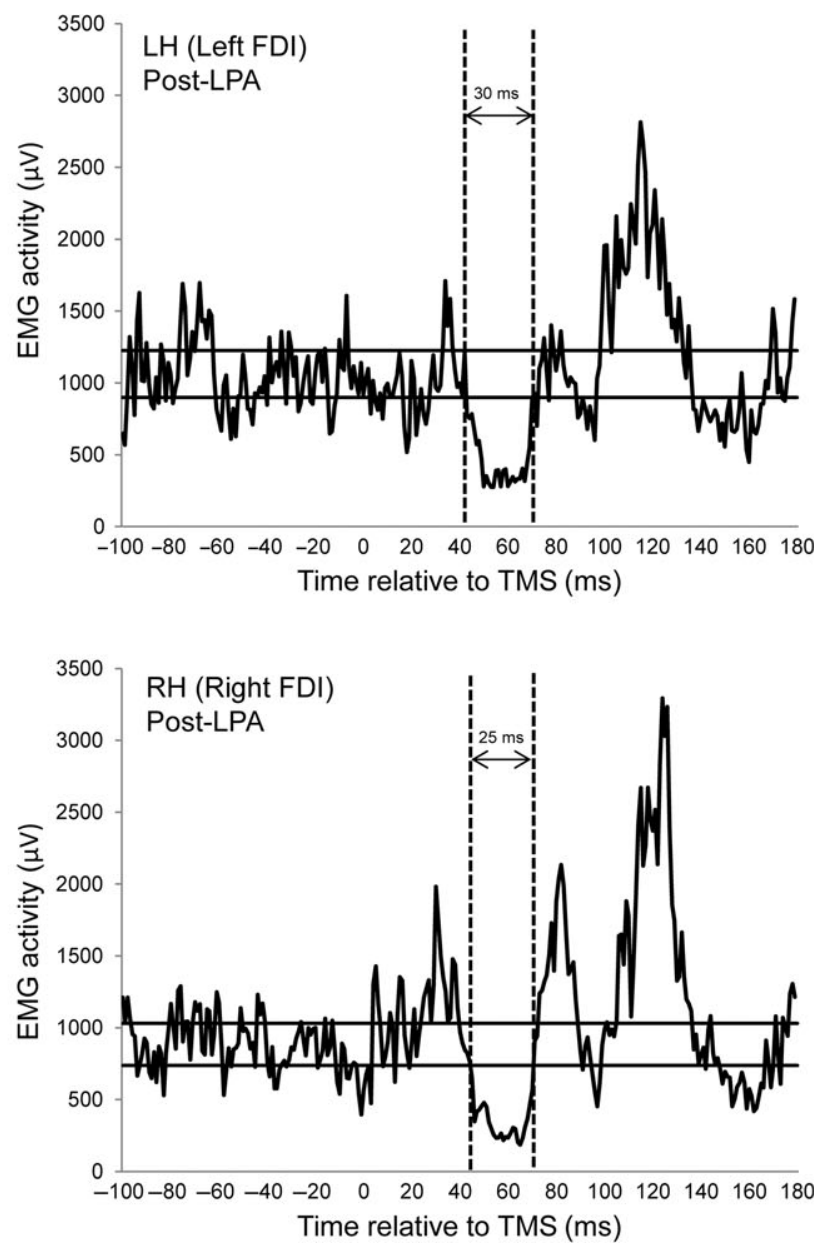

Figure 2. Examples of iSP measurements from one representative subject in the LPA group separated by Session (pre-PA and post-PA) and Hemisphere (LH (left FDI)upper row, and RH (right FDI)-bottom row). All data are averages of 20 single-trial rectified sweeps with TMS applied at time 0 . Horizontal lines indicate the upper and lower variation limits of the prestimulus EMG level. Vertical dashed lines indicate iSP onset and offset. 
2008) without affecting sensorimotor after-effects (Pisella et al. 2004). Further support for this idea comes from evidence showing that the cerebellum plays a crucial role in sensorimotor adaptation (Weiner et al. 1983; Pisella et al. 2005), that cerebellar stimulation can modulate intracortical circuits within the contralateral M1 (Chen 2004; Daskalakis et al. 2004), and that RPA and LPA produce equal increases in intracortical-facilitation (ICF) but in opposite M1s (Magnani et al. 2014).

Before PA, we observed no differences between the right-toleft and left-to-right silent periods nor between silent periods in the LPA and RPA groups. This is in agreement with a previous study showing that motor IHI is symmetric both at rest and during sustained unimanual contraction (Nelson et al. 2009) and shows that our results cannot be explained by betweengroup differences before PA. They also cannot be ascribed to the use of the right arm during the adaptation procedure or to changes in corticospinal excitability, as subjects in both the LPA and RPA groups used their right arm and MEPs elicited in the contralateral hand were unchanged after PA (see also Magnani et al. 2014).

The origin of the asymmetrical effects of LPA and RPA on cognition has long been attributed to RH specialization for visuospatial cognition and attention (Fink et al. 2000; Corbetta and Shulman 2002). The present results suggest that the source of this asymmetry could, at least in part, also lie in differences in IHI between the parietal cortices, as only the right PPC seems to inhibit its homolog (Koch et al. 2011). The specificity of PAinduced changes in IHI (found only following LPA and only from the LH to the $\mathrm{RH}$ ) would be predicted if LPA increased right-to-left parietal IHI and produced the follow-on effects of an increase in LH parietal-to-motor connectivity and internal circuits of left M1 (Rivera-Urbina et al. 2015). The direct action of PA on parietal-to-motor connectivity in the hemisphere contralateral to the prism deviation cannot explain the specificity of our effect for LPA as this pathway would predict a very different pattern of results from what we observed. Namely, opposite increases in motor IHI after "both" LPA and RPA, with the LPA increase occurring from right-to-left and not from leftto-right as in our data. Indeed, we did not predict this possibility because a previous study showed that inhibition of left PPC by cathodal (inhibitory) tDCS did not alter intracortical motor circuits in left M1 as measured by SICI or ICF (Rivera-Urbina et al. 2015). This, together with the fact that observing a change after LPA only is coherent with behavioral changes on visuospatial tasks after LPA but not RPA, leads us to suggest that the change in IHI we observed at the motor level is the result of a chain of LPA-induced modifications that include changes in parietal IHI.

\section{Implications for Models of Neglect and Neglect-Like After-Effects of PA}

Theoretical models of attention account for the fact that neglect occurs preferentially after RH damage by postulating hemispheric dominance in attentional allocation across space (either in the LH, Kinsbourne 1977, or in the RH, Heilman and Van Den Abell 1980; Mesulam 1981; Cohen et al. 1994). The recent finding by Koch et al. (2011) that the right (but not the left) PPC inhibits its homolog suggests that there might be another mechanism at play in the processes underlying neglect and PA. Asymmetrical IHI could contribute to the preferential occurrence of neglect after RH damage as well as observations that left PPC damage can produce subclinical attentional deficits without a diagnosis of clinical neglect (Karnath et al. 2002;
Beis et al. 2006). Indeed, when asymmetries in IHI are added to the Hemispheric Rivalry model, damage to both the right and left PPC would directly weaken attention toward the contralesional space, but only right PPC damage would alter IHI, resulting in hyper-activation of the left PPC and an exacerbation of the rightward attentional bias.

Asymmetric IHI could also explain why only LPA modifies spatial cognition in healthy subjects (Colent et al. 2000; Michel et al. 2003; Schintu et al. 2014). Similar to an RH lesion (Corbetta et al. 2005), LPA would inhibit the right PPC that would subsequently reduce right-to-left parietal IHI and then produce hyperactivity of the left PPC and follow-on effects in the motor cortex. In contrast, RPA would inhibit the left PPC but not alter parietal IHI and therefore produce no subsequent changes in right PPC. In neglect patients, however, the effectiveness of RPA might be due to a direct inhibitory effect on the left PPC which counteracts the left PPC hyperexcitability that is frequently observed after RH lesions (Brighina et al. 2003; Koch et al. 2008, 2012; Nyffeler et al. 2009; Cazzoli et al. 2012; Salatino et al. 2014), but which seems to depend upon the temporal epoch poststroke at which it is evaluated (acute/subacute vs. chronic; Corbetta et al. 2005; Cramer 2008; Bartolomeo and Thiebaut De Schotten 2016).

\section{Importance of Interhemispheric Connections for Both Motor and Attentional Symptoms After RH Damage}

Typically, the greater severity of motor impairments after $\mathrm{RH}$ than LH stroke (with or without a clinical diagnosis of neglect) has been attributed to attentional difficulties that are known to interfere with motor rehabilitation (Heilman et al. 1987; Buxbaum et al. 2004; Farnè et al. 2004; Di Monaco et al. 2011). When the lesion includes the right PPC we speculate that the severity of motor impairments might be due to alterations in both parietal and motor IHI. More precisely, we suggest that a decrease in right (but not left) PPC excitability (induced by a lesion, neurostimulation or LPA) has transcallosal consequences at the motor level. These consequences could lead to persistent modifications in frontal areas, even though left PPC hyperactivity seems to gradually decrease after the subacute phase (Corbetta et al. 2005; Cramer 2008).

In hemiparetic patients, no hemispheric asymmetry in the severity of motor impairments has been observed when stroke affects subcortical structures or M1 (Hendricks et al. 2002). When the lesion includes the right but not the left PPC, motor impairments might be more severe because of an exacerbation of the imbalance in motor IHI (Murase et al. 2004; Hummel and Cohen 2006). In nonhemiparetic patients, lesions including the right (but not left) PPC could have deleterious effects on motor control by inducing an asymmetry in IHI at the motor level. While speculative, it is plausible that an imbalance in motor IHI contributes to high-level motor deficits like underuse of the contralesional side of the body and/or bradykinesia and hypokinesia when moving an ipsilesional body part into contralesional hemispace, both of which have been described in the context of neglect (Mattingley et al. 1992, 1998; but see Bisiach et al. 1990, 1995, 1998; Bartolomeo et al. 1998, for a discussion of the possible dissociation between perceptual and response biases in neglect).

Finally, the proposed importance of interhemispheric connections in the severity of motor symptoms in the acute/ subacute phase of stroke (Traversa et al. 1997; Delvaux et al. 2003; Di Lazzaro et al. 2010) parallels that which has been confirmed for the severity and recovery of attentional symptoms in neglect patients. While "intra"hemispheric fronto-parietal 
disconnection is a well-established factor in both the emergence and chronic persistence of neglect (Thiebaut de Schotten et al. 2005; Bartolomeo et al. 2007), recent data suggest that "inter"hemispheric disconnection is also important (Lunven et al. 2015). Lunven et al. (2015) highlight an important role of interhemispheric communication for neglect recovery but when they compared subacute patients with and without neglect, both intrahemispheric and interhemispheric integrity were decreased in the neglect group. Together with previous studies (Gaffan and Hornak 1997; Park et al. 2006; Tomaiuolo et al. 2010), this demonstrates the importance of interhemispheric disconnection, as well as RH damage, in the genesis of neglect. This idea is in accordance with studies showing that neglect severity correlates with microstructural damage to transcallosal fibers in the posterior portion of the corpus callosum (Bozzali et al. 2012; Umarova et al. 2014) and with interhemispheric resting-state functional connectivity (Corbetta et al. 2005; Carter et al. 2012).

Our model clearly emphasizes an important role of LH hyperactivity in neglect genesis and PA-induced amelioration. It is supported by several experimental and clinical observations (discussed above) and is appealing because of its simplicity. However, LH hyperactivity remains controversial (see Bartolomeo 2015 for a review). For example, behavioral markers of LH frontal hyperactivity do not always correlate with neglect severity (Bartolomeo and Chokron 1999), and some studies have even reported a link between neglect recovery and an increase in both LH and RH activity (Luauté et al. 2006; Saj et al. 2013). In addition, TMS studies in healthy subjects (Ricci et al. 2012; Bagattini et al. 2015) have shown that inhibition of the inferior (ventral) part of the right PPC decreases left PPC activity. Note, however, that Bagattini et al. (2015) put forward the idea that this left PPC decrease does not preclude alterations in IHI at the level of the superior (dorsal) part of the PPC. The origin of this controversy might indeed lie in where the LH hyperexcitability is measured. Finally, it is clearly an oversimplification to consider that processes perturbing or rebalancing spatial behavior express themselves exclusively as alterations in mutual IHI (see Corbetta et al. 2005; Martín-Arévalo et al. 2016). Rather, "callosal connections are likely to exert both excitatory and inhibitory effects (mostly through interneurons) on the opposite hemisphere" (Bartolomeo 2015, p. 311). Thus, a more sophisticated and dynamic model of visuospatial attention networks that integrates both intrahemispheric and interhemispheric interactions is needed to understand the action mechanisms of LPA in healthy individuals and of RPA in neglect patients, as well as the complex processes that lead to neglect's attentional and motor symptoms.

In conclusion, the current results provide the first direct demonstration that PA affects IHI. They highlight the crucial role of interhemispheric interactions in visuospatial attention in general, and more specifically, in visuospatial and motor components of neglect.

\section{Funding}

This work was performed at the Neuro-immersion platform and supported by the Labex/Idex ANR-11-LABX-0042, IHU CeSaMe ANR-10-IBHU-0003 and by grants from the Fondation pour la Recherche Médicale (FRM) and the James S. McDonnell Foundation. E.M.-A. was supported by funding from FRM (SPF20140129218). A.F. and S.S. were supported by a James S. McDonnell Scholar Award.

\section{Notes}

We thank Catherine Mercier and Martin Gagné for their advice and for providing scripts for both data acquisition and analysis. Conflict of Interest: None declared.

\section{References}

Bagattini C, Mele S, Brignani D, Savazzi S. 2015. No causal effect of left hemisphere hyperactivity in the genesis of neglectlike behavior. Neuropsychologia. 72:12-21.

Bartolomeo P. 2015. Spatially biased decisions: toward a dynamic interactive model of visual neglect. In: Tracy JI, Hampstead BM, Sathian K, editors. Plasticity of cognition in neurologic disorders. Oxford: Oxford University Press. p. 299-322.

Bartolomeo P, Chokron S. 1999. Left unilateral neglect or right hyperattention? Neurology. 53:2023-2027.

Bartolomeo P, D'Erme P, Perri R, Gainotti G. 1998. Perception and action in hemispatial neglect. Neuropsychologia. 36:227-237.

Bartolomeo P, Thiebaut De Schotten M. 2016. Let thy left brain know what thy right brain doeth: Inter-hemispheric compensation of functional deficits after brain damage. Neuropsychologia (In Press). DOI:10.1016/j.neuropsychologia. 2016.06.016.

Bartolomeo P, Thiebaut de Schotten M, Doricchi F. 2007. Left unilateral neglect as a disconnection syndrome. Cereb Cortex. 17:2479-2490.

Beis JM, Keller C, Morin N, Bartolomeo P, Bernati T, Chokron S, Leclercq M, Louis-Dreyfus A, Marchal F, Martin Y, et al. 2006. Right spatial neglect after left hemisphere stroke. Neurology. 63:1600-1605.

Bisiach E, Geminiani G, Berti A, Rusconi ML. 1990. Perceptual and premotor factors of unilateral neglect. Neurology. 40: 1278-1281.

Bisiach E, Ricci R, Lualdi M, Colombo MR. 1998. Perceptual and response bias in unilateral neglect: two modified versions of the Milner landmark task. Brain Cogn. 37:369-386.

Bisiach E, Tegnér R, Làdavas E, Rusconi ML, Mijović D, Hjaltason H. 1995. Dissociation of ophtalmokinetic and melokinetic attention in unilateral neglect. Cereb Cortex. 5:439-447.

Bjoertomt O, Cowey A, Walsh V. 2002. Spatial neglect in near and far space investigated by repetitive transcranial magnetic stimulation. Brain. 125:2012-2022.

Bozzali M, Mastropasqua C, Cercignani M, Giulietti G, Bonnì S, Caltagirone C, Koch G. 2012. Microstructural damage of the posterior corpus callosum contributes to the clinical severity of neglect. PLoS One. 7:e48079.

Brighina F, Bisiach E, Oliveri M, Piazza A, La Bua V, Daniele O, Fierro B. 2003. $1 \mathrm{~Hz}$ repetitive transcranial magnetic stimulation of the unaffected hemisphere ameliorates contralesional visuospatial neglect in humans. Neurosci Lett. 336:131-133.

Buxbaum LJ, Ferraro MK, Veramonti T, Farnè A, Whyte J, Làdavas E, Frassinetti F, Coslett HB. 2004. Hemispatial neglect: Subtypes, neuroanatomy, and disability. Neurology. 9 (62):749-756.

Carter AR, Shulman GL, Corbetta M. 2012. Why use a connectivity-based approach to study stroke and recovery of function? NeuroImage. 62:2271-2280.

Cazzoli D, Muri RM, Schumacher R, von Arx S, Chaves S, Gutbrod $\mathrm{K}$, Bohlhalter S, Bauer D, Vanbellingen T, Bertschi M, et al. 2012. Theta burst stimulation reduces disability during the activities of daily living in spatial neglect. Brain. 135:3426-3439.

Chao CC, Karabanov AN, Paine R, Campos AC, Kukke SN, Wu T. 2013. Induction of motor association plasticity in the posterior 
parietal cortex-primary motor network. Cereb Cortex. 5: 526-532.

Chen R. 2004. Interactions between inhibitory and excitatory circuits in the human motor cortex. Exp Brain Res. 154:1-10.

Chen R, Yung D, Li JY. 2003. Organization of ipsilateral excitatory and inhibitory pathways in the human motor cortex. J Neurophysiol. 89:1256-1264.

Cohen JD, Romero RD, Farah MJ, Servan-Schreiber D. 1994. Mechanisms of spatial attention: the relation of macrostructure to microstructure in parietal neglect. J Cogn Neurosci. 6 : 377-387.

Colent C, Pisella L, Bernieri C, Rode G, Rossetti Y. 2000. Cognitive bias induced by visuo-motor adaptation to prisms: a simulation of unilateral neglect in normal individuals? Neuroreport. 11:1899-1902.

Corbetta M, Kincade MJ, Lewis C, Snyder AZ, Sapir A. 2005. Neural basis and recovery of spatial attention deficits in spatial neglect. Nat Neurosci. 8:1603-1610.

Corbetta M, Shulman GL. 2002. Control of goal-directed and stimulus-driven attention in the brain. Nat Rev Neurosci. 3: 201-215.

Cramer SC. 2008. Repairing the human brain after stroke: I. Mechanisms of spontaneous recovery. Ann Neurol. 63:272-287.

Crottaz-Herbette S, Fornari E, Clarke S. 2014. Prismatic adaptation changes visuospatial representation in the inferior parietal lobule. J Neurosci. 34:11803-11811.

Daskalakis Z, Molnar GF, Christensen BK, Sailer A, Fitzgerald PB, Chen R. 2003. An automated method to determine the transcraneal magnetic stimulation-induced contralateral silent period. Clin Neurophysiol. 114:938-944.

Daskalakis ZJ, Paradiso GO, Christensen BK, Fitzgerald PB, Gunraj C, Chen R. 2004. Exploring the connectivity between the cerebellum and motor cortex in humans. J Physiol. 552: 689-700.

Delvaux V, Alagona G, Gerard P, De Pasqua V, Pennisi G, de Noordhout AM. 2003. Post-stroke reorganization of hand motor area: a 1-year prospective follow-up with focal transcranial magnetic stimulation. Clin Neurophysiol. 114: 1217-1225.

Di Lazzaro V, Profice P, Pilato F, Capone F, Ranieri F, Pasqualetti P, Colosimo C, Pravata E, Cianfoni A, Dileone M. 2010. Motor cortex plasticity predicts recovery in acute stroke. Cereb Cortex. 20:1523-1528.

Di Lazzaro V, Restuccia D, Oliviero A, Profice P, Ferrara L, Insola A, Mazzone P, Tonali P, Rothwell JC. 1998. Magnetic transcranial stimulation at intensities below active motor threshold activates intracortical inhibitory circuits. Exp Brain Res. 119: 265-268.

Di Monaco M, Schintu S, Dotta M, Barba S, Tappero R, Gindri P. 2011. Severity of unilateral spatial neglect is an independent predictor of functional outcome after acute inpatient rehabilitation in individuals with right hemispheric stroke. Arch Phys Med Rehabil. 92:1250-1256.

Farnè A, Buxbaum LJ, Ferraro M, Frassinetti F, Whyte J, Veramonti T, Angeli V, Coslett HB, Làdavas E. 2004. Patterns of spontaneous recovery of neglect and associated disorders in acute right brain-damaged patients. J Neurol Neurosurg Psychiatry. 75:1401-1410.

Farnè A, Rossetti Y, Toniolo S, Làdavas E. 2002. Ameliorating neglect with prism adaptation: visuo-manual and visuoverbal measures. Neuropsychologia. 40:718-729.

Fierro B, Brighina F, Oliveri M, Piazza A, La Bua V, Buffa D, Bisiach E. 2000. Contralateral neglect induced by right posterior parietal rTMS in healthy subjects. Neuroreport. 11: 1519-1521.

Fink GR, Marshall JC, Shah NJ, Weiss PH, Halligan PW, GrosseRuyken M, Ziemons K, Zilles K, Freund HJ. 2000. Line bisection judgments implicate right parietal cortex and cerebellum as assessed by fMRI. Neurology. 28:1324-1331.

Fling BW, Benson BL, Seider RD. 2013. Transcallosal sensorimotor fiber tract structure-function relationships. Hum Brain Mapp. 34:384-395.

Frassinetti F, Angeli V, Meneghello F, Avanzi S, Làdavas E. 2002. Long-lasting amelioration of visuospatial neglect by prism adaptation. Brain. 125:608-623.

Gaffan D, Hornak J. 1997. Visual neglect in the monkey. Representation and disconnection. Brain. 120:1647-1657.

Garvey MA, Ziemann U, Becker DA, Barker CA, Bartko JJ. 2001. New graphical method to measure silent periods evoked by transcranial magnetic stimulation. Clin Neurophysiol. 112: 1451-1460.

Giglia G, Mattaliano P, Puma A, Rizzo S, Fierro B, Brighina F. 2011. Neglect-like effects induced by tDCS modulation of posterior parietal cortices in healthy subjects. Brain Stimul. 4:294-299.

Giovannelli F, Borgheresi A, Balestrieri F, Zaccara G, Viggiano MP, Cincotta M, Ziemann U. 2009. Modulation of interhemispheric inhibition by volitional motor activity: an ipsilateral silent period study. J Physiol. 587 (Pt 22):5393-5410.

He BJ, Snyder AZ, Vincent JL, Epstein A, Shulman GL, Corbetta M. 2007. Breakdown of functional connectivity in frontoparietal networks underlies behavioral deficits in spatial neglect. Neuron. 53:905-918.

Heilman KM, Bowers D, Valenstein E, Watson RT. 1987. Hemispace and hemispatial neglect. In: Jeannerod IM, editor. Neurophysiological and neuropsychological aspects of spacial neglect. Amsterdam, Holland: Elsevier. p. 115-150.

Heilman KM, Van Den Abell T. 1980. Right hemisphere dominance for attention: the mechanism underlying hemispheric asymmetries of inattention (neglect). Neurology. 30:327-330.

Hendricks HT, van Limbeek J, Geurts AC, Zwarts MJ. 2002. Motor recovery after stroke: a systematic review of the literature. Arch Phys Med Rehabil. 83:1629-1637.

Hummel FC, Cohen LG. 2006. Non-invasive brain stimulation: a new strategy to improve neurorehabilitation after stroke? Lancet Neurol. 5:708-712.

Jacobs S, Brozzoli C, Farnè A. 2012. Neglect: a multisensory deficit? Neuropsychologia. 50:1029-1044.

Jung P, Ziemann U. 2006. Differences of the ipsilateral silent period in small hand muscles. Muscle Nerve. 34:431-436.

Karabanov AN, Chao CC, Paine R, Hallet M. 2012. Mapping different intra-hemisphere parietal-motor networks using twin coil TMS. Brain Stimul. 6:384-389.

Karnath HO, Milner AD, Vallar G. 2002. The cognitive and neural bases of spatial neglect. Oxford: Oxford University Press.

Kinsbourne M. 1970. A model for the mechanism of unilateral neglect of space. Trans Am Neurol Assoc. 95:143-146.

Kinsbourne M. 1973. The control of attention by interaction between the cerebral hemispheres. In: Kornblum S, editor. Attention and performance IV. New York: Academic Press. p. 239-256.

Kinsbourne M. 1977. Hemi-neglect and hemisphere rivalry. In: Weinstein EA, Friedland RP, editors. Hemi-inattention and hemisphere specialization. New York: Raven Press. p. 41-49. 
Kinsbourne M. 1987. Mechanisms of unilateral neglect. In: Jeannerod M, editor. Neurophysiological and neuropsychological aspects of spatial neglect. Amsterdam: Elsevier Science Publishers. p. 69-86.

Koch G, Cercignani M, Bonnì S, Giacobbe V, Bucchi G, Versace V, Caltagirone C, Bozzali M. 2011. Asymmetry of parietal interhemispheric connections in humans. J Neurosci. 31:8967-8975.

Koch G, Oliveri M, Cheeran B, Ruge D, Lo Gerfo E, Salerno S, Torriero S, Marconi B, Mori F, Driver J, et al. 2008. Hyperexcitability of parietal-motor functional connections for the intact left-hemisphere in neglect patients. Brain. 131: 3147-3155.

Koch G, Veniero D, Caltagirone C. 2012. To the other side of the neglected brain: the hyperexcitability of the left intact hemisphere. Neuroscientist. 19:208-217.

Làdavas E, Giulietti S, Avenanti A, Bertini C, Lorenzini E, Quinquinio C, Serino A. 2015. a-tDCS on the ipsilesional parietal cortex boosts the effects of prism adaptation treatment in neglect. Restor Neurol Neurosci. 33:647-662.

Luauté J, Michel C, Rode G, Pisella L, Jacquin-Courtois S, Costes N, Cotton F, le Bars D, Boisson D, Halligan P, et al. 2006. Functional anatomy of the therapeutic effects of prism adaptation on left neglect. Neurology. 27:1859-1867.

Lunven M, Thiebaut De Schotten M, Bourlon C, Duret C, Migliaccio R, Rode G, Bartolomeo P. 2015. White matter lesional predictors of chronic visual neglect: a longitudinal study. Brain. 138:746-760.

Magnani B, Caltagirone C, Oliveri M. 2014. Prismatic adaptation as a novel tool to directionally modulate motor cortex excitability: evidence from paired-pulse TMS. Brain Stimul. 7:573-579.

Martín-Arévalo E, Laube I, Koun E, Farnè A, Reilly KT, Pisella L. 2016. Prism adaptation alters electrophysiological markers of attentional processes in the healthy brain. J Neurosci. 36: 1019-1030.

Mattingley JB, Bradshaw JL, Phillips JG. 1992. Impairments of movement initiation and execution in unilateral neglect. Brain. 115:1849-1874

Mattingley JB, Husain M, Rorden C, Kennard C, Driver J. 1998. Motor role of human inferior parietal lobe revealed in unilateral neglect patients. Nature. 392:179-182.

Meyer BU, Röricht S, Grafin von Einsiedel H, Kruggel F, Weindl A. 1995. Inhibitory and excitatory interhemispheric transfers between motor cortical areas in normal humans and patients with abnormalities of the corpus callosum. Brain. 118:429-440.

Meyer BU, Röricht S, Woiciechowsky C. 1998. Topography of fibers in the human corpus callosum mediating interhemispheric inhibition between the motor cortices. Ann Neurol. 43:360-369.

Mesulam M-M. 1981. A cortical network for directed attention and unilateral neglect. Ann Neurol. 10:309-325.

Michel C, Pisella L, Halligan PW, Luauté J, Rode G, Boisson D, Rossetti Y. 2003. Simulating unilateral neglect in normals using prism adaptation: implications for theory. Neuropsychologia. 41:25-39.

Murase N, Duque J, Mazzocchio R, Cohen LG. 2004. Influence of interhemispheric interactions on motor function in chronic stroke. Ann Neurol. 55:400-409.

Nelson AJ, Hoque T, Gunraj C, Ni Z, Chen R. 2009. Bi-directional interhemispheric inhibition during unimanual sustained contractions. BMC Neurosci. 10:1-13.

Nijboer TC, Vree A, Dijkerman HC, Van der Stigchel S. 2010. Prism adaptation influences perception but not attention: evidence from antisaccades. Neuroreport. 21:386-389.
Nyffeler T, Cazzoli D, Hess CW, Muri RM. 2009. One session of repeated parietal theta burst stimulation trains induces long-lasting improvement of visual neglect. Stroke. 40: 2791-2796.

Nyffeler T, Cazzoli D, Wurtz P, Lüthi M, von Wartburg R, Chaves S, Déruaz A, Hess CW, Müri RM. 2008. Neglect-like visual exploration behaviour after theta burst transcranial magnetic stimulation of the right posterior parietal cortex. Eur J Neurosci. 27:1809-1813.

Oldfield RC. 1971. The assessment and analysis of handedness: the Edinburgh Inventory. Neuropsychologia. 9:97-113.

Oliveri M, Bisiach E, Brighina F, Piazza A, La Bua V, Buffa D, Fierro B. 2001. rTMS of the unaffected hemisphere transiently reduces contralesional visuospatial hemineglect. Neurology. 57:1338-1340.

Park KC, Lee BH, Kim EJ, Shin MH, Choi KM, Yoon SS, Kwon SU, Chung CS, Lee KH, Heilman KM, et al. 2006. Deafferentationdisconnection neglect induced by posterior cerebral artery infarction. Neurology. 66:56-61.

Pisella L, Michel H, Gréa C, Tilikete C, Vighetto A, Rossetti Y. 2004. Preserved prism adaptation in bilateral optic ataxia: strategic versus adaptive reaction to prisms. Exp Brain Res. 156:399-408.

Pisella L, Rode G, Farnè A, Boisson D, Rossetti Y. 2002. Dissociated long lasting improvements of straight-ahead pointing and line bisection tasks in two hemineglect patients. Neuropsychologia. 40:327-334.

Pisella L, Rode G, Farnè A, Tilikete C, Rossetti Y. 2006. Prism adaptation in the rehabilitation of patients with visuospatial cognitive disorders. Curr Opin Neurol. 19:534-542.

Pisella L, Rossetti Y, Michel C, Rode G, Boisson D, Pélisson D, Tilikete C. 2005. Ipsidirectional impairment of prism adaptation after unilateral lesion of anterior cerebellum. Neurology. 65:150-152.

Redding GM, Wallace B. 2006. Prism adaptation and unilateral neglect: Review and analysis. Neuropsychologia. 44:1-20.

Ricci R, Salatino A, Li X, Funk AP, Logan SL, Mu Q Johnson KA, Bohning DE, George MS. 2012. Imaging the neural mechanisms of TMS neglect-like bias in healthy volunteers with the interleaved TMS/fMRI technique: preliminary evidence. Front Hum Neurosci. 6:326

Rivera-Urbina GN, Batsikadze G, Molero-Chamizo A, Paulus W, Kuo MF, Nitsche MA. 2015. Parietal transcranial direct current stimulation modulates primary motor cortex excitability. Eur J Neurosci. 41:845-855.

Rossetti Y, Rode G, Pisella L, Farnè A, Li L, Boisson D, Perenin MT. 1998. Prism adaptation to a rightward optical deviation rehabilitates left hemispatial neglect. Nature. 395:166-169.

Rossini PM, Burke D, Chen R, Cohen L, Daskalakis Z, Di Iorio R, Di Lazzaro V, Ferreri F, Fitzgerald PB, George MS, et al. 2015. Non-invasive electrical and magnetic stimulation of the brain, spinal cord, roots and peripheral nerves: Basic principles and procedures for routine clinical and research application. An updated report from an I.F.C.N. Committee. Clin Neurophysiol. 126:1071-1107.

Saj A, Cojan Y, Vocat R, Luauté J, Vuilleumier P. 2013. Prism adaptation enhances activity of intact fronto-parietal areas in both hemispheres in neglect patients. Cortex. 49:107-119.

Salatino A, Berra E, Troni W, Sacco K, Cauda F, D'Agata F, Geminiani G, Duca S, Dimanico U, Ricci R. 2014. Behavioral and neuroplastic effects of low-frequency rTMS of the unaffected hemisphere in a chronic stroke patient: a concomitant TMS and fMRI study. Neurocase. 20:615-626. 
Schintu S, Pisella L, Jacobs S, Salemme R, Reilly KT, Farnè A. 2014. Prism adaptation in the healthy brain: the shift in line bisection judgments is long lasting and fluctuates. Neuropsychologia. 53:165-170.

Schmierer K, Niehaus L, Röricht S, Meyer BU. 2000. Conduction deficits of callosal fibres in early multiple sclerosis. J Neurol Neurosurg Psychiatry. 68:633-638.

Serino A, Angeli V, Frassinetti F, Làdavas E. 2006. Mechanisms underlying neglect recovery after prism adaptation. Neuropsychologia. 44:1068-1078.

Stinear CM, Petoe MA, Byblowb WD. 2015. Primary motor cortex excitability during recovery after stroke: implications for neuromodulation. Brain Stimul. 8:1183-1190.

Striemer CL, Blangero A, Rossetti Y, Boisson D, Rode G, Salemme R, Vighetto A, Pisella L, Danckert J. 2008. Bilateral parietal lesions disrupt the beneficial effects of prism adaptation: evidence from a patient with optic ataxia. Exp Brain Res. 187:295-302.

Striemer CL, Danckert JA. 2010. Through a prism darkly: re-evaluating prisms and neglect. Trends Cogn Sci. 14: 308-316.

Striemer CL, Sablatnig J, Danckert JA. 2006. Differential influences of prism adaptation on reflexive and voluntary covert attention. J Int Neuropsychol Soc. 12:337-349.

Szczepanski SM, Kastner S. 2013. Shifting attentional priorities: control of spatial attention through hemispheric competition. J Neurosci. 33:5411-5421.

Thiebaut de Schotten M, Urbanski M, Duffau H, Volle E, Lévy R, Dubois B, Bartolomeo P. 2005. Direct evidence for a parietalfrontal pathway subserving spatial awareness in humans. Science. 5744:2226-2228.
Tomaiuolo F, Voci L, Bresci M, Cozza S, Posteraro F, Oliva M, Doricchi F. 2010. Selective visual neglect in right brain damaged patients with splenial interhemispheric disconnection. Exp Brain Res. 206:209-217.

Traversa R, Cicinelli P, Bassi A, Rossini PM, Bernardi G. 1997. Mapping of motor cortical reorganization after stroke. A brain stimulation study with focal magnetic pulses. Stroke. 28:110-117.

Triggs WJ, Calvanio R, Macdonell RAL, Cros D, Chiappa KH. 1994. Physiological motor asymmetry in human handedness: evidence from transcranial magnetic stimulation. Brain Res. 636:270-476.

Umarova RM, Reisert M, Beier TU, Kiselev VG, Klöppel S, Kaller CP, Glauche V, Mader I, Beume I, Hennig J, et al. 2014. Attentionnetwork specific alterations of structural connectivity in the undamaged white matter in acute neglect. Hum Brain Mapp. 35:4678-4692.

Vallar G. 1993. The anatomical basis of spatial hemineglect in humans. In: Robertson IH, Marshall JC, editors. Unilateral neglect: clinical and experimental studies. Hove, UK: Lawrence Erlbaum Associates. p. 27-59.

Weiner MJ, Hallet M, Funkenstein HH. 1983. Adaptation to lateral displacement of vision in patients with lesions of the central nervous system. Neurology. 33:766-772.

Wittstock M, Wolters A, Benecke R. 2007. Transcallosal inhibition in amyotrophic lateral sclerosis. Clin Neurophysiol. 118:301-307.

Wolters A, Classen J, Kunesch E, Grossmann A, Benecke R. 2004. Measurements of transcallosally mediated cortical inhibition for differentiating parkinsonian syndromes. Mov Disord. 19:518-528. 